Supporting Information

\title{
Biobased Tannic Acid Cross-linked Epoxy Thermosets with Hierarchical Molecular Structure and Tunable Properties: Damping, Shape Memory, and Recyclability
}

\author{
Xiaming Feng, Jizhou Fan, Ang Li, Guoqiang Li* \\ Department of Mechanical \& Industrial Engineering, Louisiana State University, \\ Baton Rouge, Louisiana 70803, United States \\ *Corresponding author. E-mail: lguoqi1@lsu.edu; Tel.: 001-225-578-5302
}

Number of pages: 6

Number of figures: 5

Number of tables: 0 


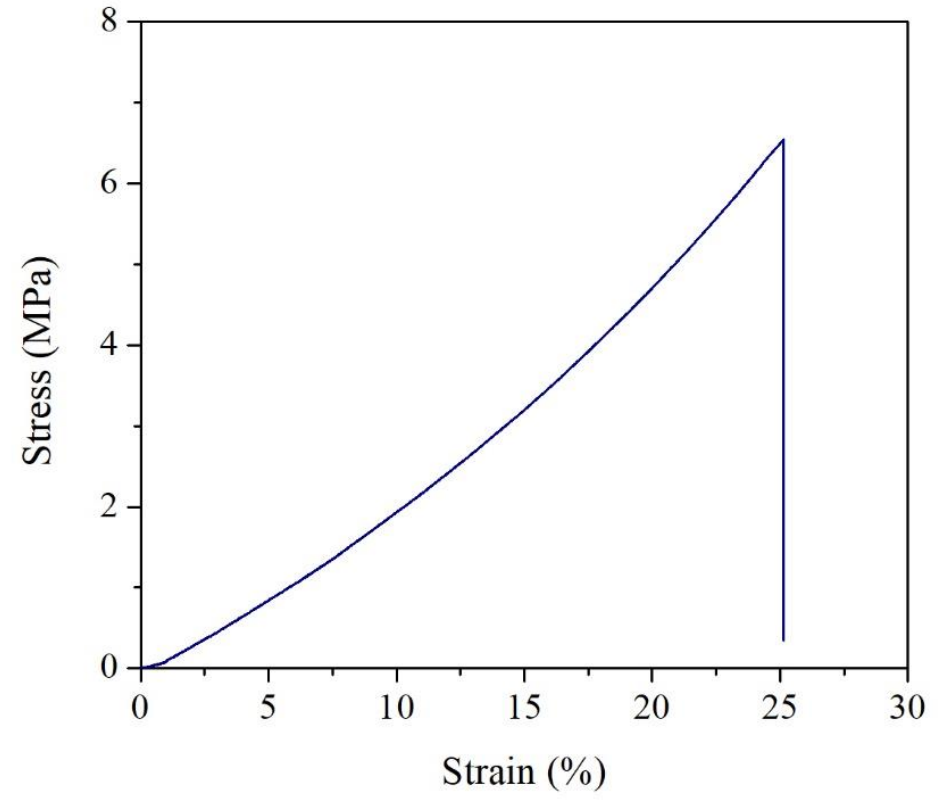

Figure S1. The first compressive programming stress-strain profile the TAEP-1.0 sample. 


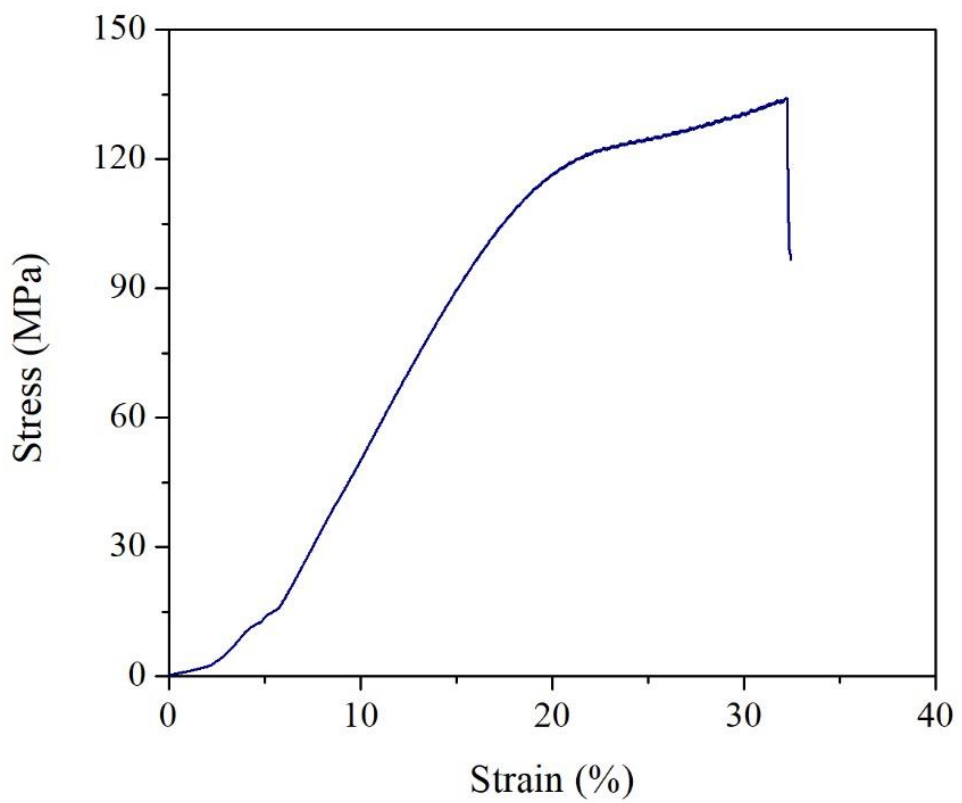

Figure S2. Compressive property of the directly mixed and cured TAEP-1.0 sample at room temperature. 


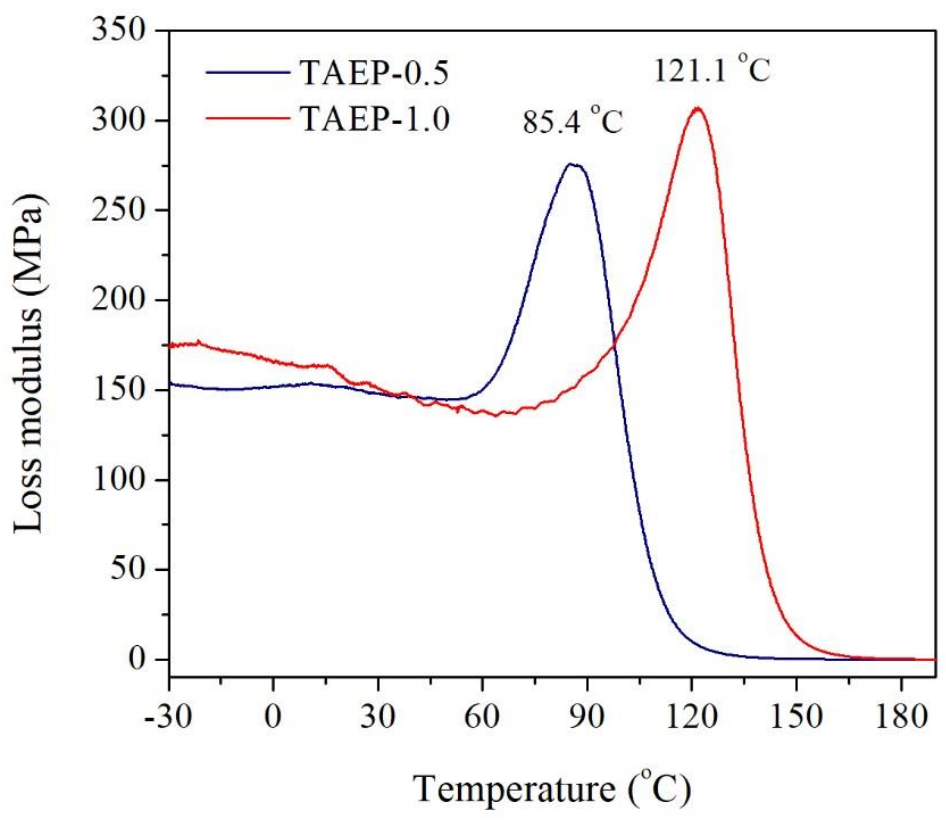

Figure S3. Temperature dependence of loss modulus for the TAEP-0.5 and TAEP-1.0 at $1 \mathrm{~Hz}$. 


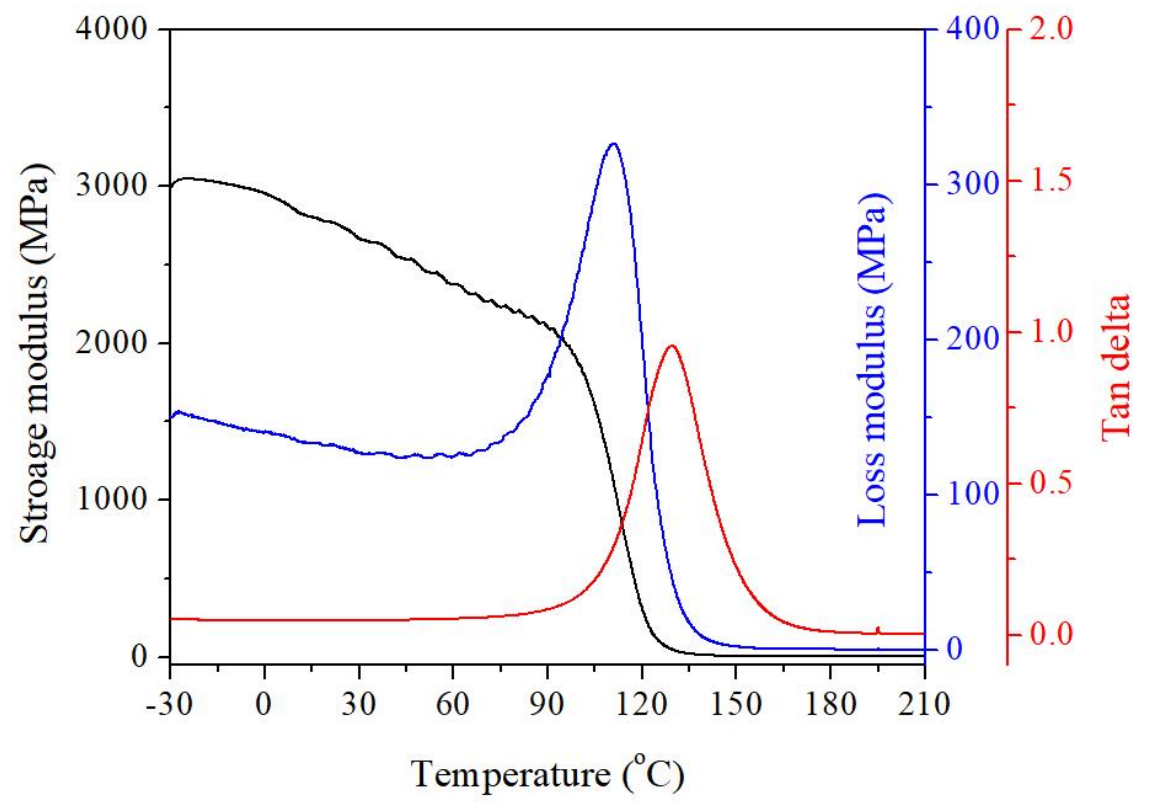

Figure S4. DMA results of the TAEP-1.0 after post-curing at $175{ }^{\circ} \mathrm{C}$ for $2 \mathrm{~h}$. 

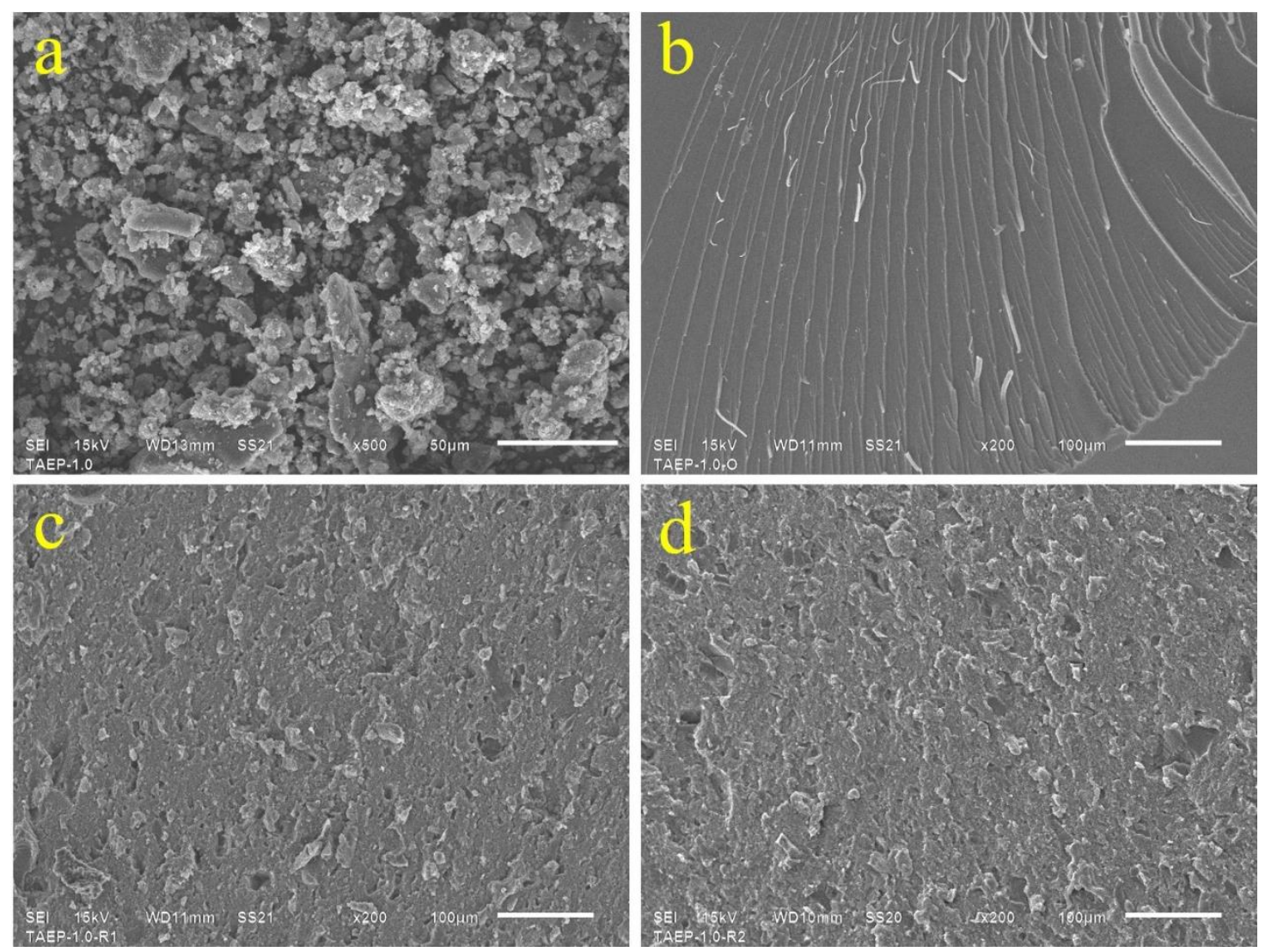

Figure S5. SEM images of ball milled TAEP-1.0 powders (a), TAEP-1.0 samples before (b) and after recycling process at different conditions $\left(180{ }^{\circ} \mathrm{C} / 2 \mathrm{~h}, 210^{\circ} \mathrm{C} / 4 \mathrm{~h}\right)(\mathrm{c}$ and d), respectively. 